\title{
The Study of Chinese-English Trademark Translation
}

\author{
Xuechuan $\mathrm{He}$ \\ Shanxi Normal University, Linfen, China
}

\begin{abstract}
Trademark is a symbol of products and the core of commodity culture. Most of trademarks have specific national cultural connotation. If commodity be seen as a carrier of culture transmission, trademark translation must pay more attention to differences of customs under different culture background, in order to avoid negative associations and misunderstanding. Through the analysis of specific cultural differences, this paper expounds some principles that translators should follow in English-Chinese trademark translation. And taking Chinese-English trademark translation as a starting point in this paper, we discuss the specific performance of trademark translation and analyze the cultural differences in animals, plants, colors, numbers and other aspects between Chinese and English countries, so that summarize the methods of trademark translation.
\end{abstract}

Index Terms - Trademark, translation, cultural differences

\section{INTRODUCTION}

Nowadays, trademark translation has an important position in international trade. AI Ries, an American scholar, points out that the stand or fall of translated names cause the differences in the millions of dollars in sales performance(AI Ries, 2009). However, the differences of culture produced by regional differences, living environment, thinking mode and living habits lead to people have different understanding of the concept. Therefore, if you want to get good translation of trademarks, the differences in different cultures is considered firstly. If translators cannot deal with the differences caused by culture, consumers can not understand the connotative meaning of trademarks. Good translation can improve the understanding between consumers and manufactures

First part is introduction of this paper. The value of this research is mainly introduced in first part. Second part introduces four principles of trademark translation. Third part gives concrete examples to analyze the trademark translation with words of different association, including different associations of animal, plants, colors, numeral, politics and economy. Fourth part gives examples about trademark names in cultural differences, including differences of individual thoughts, social customs, and religious belief. Fifth part analyzes the problems of Sino-British trademark translation. Firstly, translated names do not conform to the cultural connotation. Secondly, translated names are not very elegant. Thirdly, trademark names translated depend on pronunciation, some of translated words have bad meanings. Sixth part concludes some methods of trademark translation. The last part of this paper is conclusion emphasizing the theme of this research.

\section{Principles of Translation in Chinese AND ENGLish Trademarks}

Trademark is a mark used by commodity producers to make their goods different from other businesses in the market, and convey products' information to consumers. On the face of it, trademark translation is a transformation between two languages, but in fact, language is the carrier of culture, so trademark translation is a intercultural communicative activity. As the product image, trademarks often reflect different national aesthetic interests, cultural values and consumer psychology. Thus the trademark translation requires translators must have a deep understanding of the differences between two countries, and focus on the specific application between source languages and target languages. As Eugene Nida, a famous translator, pointed out that familiarity with two cultures is even more important than mastering two languages for a successful translation, because words only make sense in their cultural background. Successful trademark translation should follow some certain principles.

\section{A. Principle of Understanding Cultural Connotation}

Due to many differences of ecological environment, history, religion, politics, economy and other aspects, different countries have different values and cultural characteristics, so as to it forms a different cultural environment. The environment is rooted in cultural habits. Psychological characteristics of people are often affected by it, thus people have different consumptive psychology. It is a precondition for successful trademark translation to understand the similarities and differences in different cultures. We must understand the internal differences of different cultures in various countries and avoid misunderstandings caused by cultural differences.

\section{B. Principle of Easy to Pronounce and Remember}


The name of a trademark should be as simple as possible to make it easy to remember. (Lv Huichun., 2010)It is an important principle that trademarks are so simple and clear to make people gifted with an extraordinary retentive memory. The name of some international famous trademarks are catchy in Chinese such as 耐克(Nike), 阿迪达斯 (Adidas), 奔驰(Benz), 宝马(BMW), 奥迪(Audi) and so on. They are not only let Chinese people remember quickly, but also remember for a long time. Chinese brand name should be less than five words in translation and English brand name should not exceed three syllables. Trademark names should avoid the use of unfamiliar vocabulary. For example, "Head \& Shoulder"(the name of a kind of shampoo) has been translated into "海伦仙度丝(Hai Lun Xian Du Si)", which is too long for customers to understand. But "海飞丝(Hai Fei Si)" is more vivid and refreshing than "海伦仙度丝 (Hai Lun Xian Du Si)" for Chinese people.

\section{Principle of Combining Characteristics of Products}

The principle of combining the characteristics of products is the basic requirement in trademark translation. The brand name must conform to the nature of goods and embody the concept of commodity positioning, to accurately deliver productive information to consumers. For example, "Procter \& Gamble", a trademark of the company, is translated as "宝洁(Bao Jie)" instead of "宝碱(Bao Jian)". This name can well reflect characteristics of healthy commodity in the company.

\section{Principle of Equivalence between Literal Meaning and Implied Meaning}

If you can not achieve perfection effect, should adhere to the "Dynamic Equivalence" principle. Nida, the famous translation theorist, put forward the concept of translation equivalence. He pointed out that each language has its inherent characteristics(Nida, 1993). In the process of the implementation of trademark translation, the form and connotation of a source language should be preserved to achieve the effect of it. Because of the differences between Chinese and British culture, it is necessary for trademark translation to respect the customs and language characteristics of different consumers.

\section{E. Principle of Paying Attention to Economic and Political Connotation}

In the process of trademark translation, translators will often encounter some political and economic words that have special meanings. Because of different cultural environment, these words may enable consumers think of unnecessary negative associations. In order to safeguard the dignity and interests of the states, and better promote friendly exchanges among the people of all countries, translators should have a certain understanding and grasp of political and economic policies of all countries.

\section{Trademark Translation With Words of DifFERENT Association}

\section{A. Different Associations of Animal}

"Because of the different history and culture, there are lots of differences in the associations of animals and plants between China and English-speaking countries."(Long Lingyun, 2007, p.46) "孔雀(Kong Que)" is a brand name of Chinese color television. Chinese people associate peacock with beautiful and auspicious. So when we introduce "Peacock" color TV to China, Chinese people will form noble and elegant images in their minds. But in western countries, if we translate"孔雀(Kong Que)" into "Peacock", goods will not be favored by western people. Because "Peacock" has a hidden meaning and is universally considered to be an evil bird or a playboy. Therefore, there are "as proud as peacock" and "play the peacock" in English idioms (Liu Fagong,2003).

In Chinese traditional culture, "dragon" is a totem image. In order to express the belief and worship of "dragon" in daily life, Chinese people hold dragon boat races on the Dragon Boat Festival. As far as idioms of the dragon, they have happy and beautiful cultural connotation in Chinese learning. In western countries, however, because of the influence of Christian culture, western people think that "dragon" is a lizard with a long tail, two big wings, and it can breathe fire. Western dragon often equated with evil. Therefore, as a trademark, "dragon" will give unpleasant associations to western people.

There are a lot of examples of other animals. Bee represents the meaning of busy and diligent in Chinese. But it points an unpleasant creature in English culture. Eagle has associative meaning of hero in Chinese. But it means power and liberty in Western countries. Goat points people who has kind-hearted personality in Chinese, but represent the meaning of lecherous man in Western countries. Bat is a symbol of health and happiness in Chinese traditional customs, but it is always associated with dark forces in Western folk customs.

In addition to these, of course, there are many other examples. “大白兔(Da Bai Tu)” (candy) is a famous trademark in China. "Rabbit" is a symbol of longevity in China, but in western culture, especially in Australia, the local people do not love rabbits, because they destroy their grassland. "Bee" is a symbol of diligence and dedication in Chinese, but it mean objectionable stuff in Western countries; "Goat" is a symbol of gentle personality in Chinese, but is lecher in western countries; "Bat" is a symbol of health and happiness in Chinese traditional customs, but it has always been associated with the dark forces in Western folklore. (Lan Tiane,2014)

\section{B. Different Associations of Plants}


“松(pine)”, “竹(bamboo)”, and “梅(plum blossom)” in traditional culture Chinese called the m the three durable plants of winter. "pine, bamboo and plum blossom" are symbol of noble character, and are metaphor to faithful friendship, so “松(pine)”, “竹(bamboo)”, and “梅(plum blossom)” as a trademark word is very popular in China.Therefore "竹叶青" (beverage) and "梅花" (aginomoto) are successful examples. However, "pine", "bamboo" and "plum" are not considered in the western culture. In addition "Peony" and "Chrysanthemum" are very popular in China. The trademarks named for them can arouse people's positive associations. But in many European countries, people don't use chrysanthemums as gifts, because chrysanthemums with the meaning of death can make people think of graveyards.

\section{Different Associations of Colors}

Because of the great differences between English and Chinese cultures, the same color has very different associative meanings. In western countries, "Red "means danger, bloodshed and violence; "Yellow" means a yellow dog; "Blue" means obscene people; "Green" is used to indicate people who lack of training or experience, knowledge; "White" means pure and happy; "Black" have evil and sinister meaning in English. The same color does not have the same associative meaning in English or Chinese culture. In view of this, the two trademarks of “蓝天(Lan Tian)” and “白象 (Bai Xiang)" can not be translated literally into "Blue Sky" and "White Elephant".

\section{Different Associations of Numeral}

Because of the similarity of thinking ways, people have same or similar association to the same number. There are many differences of natural environment, customs, religious belief and the way of thinking between English and Chinese national culture, to form different characteristics of national culture. Differences of culture make people have different associative emotions to the same number. However, the same number can product same or similar association.

Different ethnic groups have different favor and taboo of numbers. "Three", "six", "eight" and "nine" are favored by Chinese people. “Three" has associative meaning of lucky, noble, and auspicious. For example, “三九胃泰(drug)” is best-selling drugs in China. The associative meaning of "Six" is smooth going. "Eight" has associative meaning of fortune, because eight has same pronunciation with “发(Fa)”. For example, “八宝弹(porridge)” is a kind of delicious food in China. And the trademark name of " $361^{\circ}$ (sportswear)" is very popular in China. "Nine" has associative meaning of forever. Because it has similar pronunciation with “久(Jiu)". The trademark name of "999 (medicine)" is an typical example in China. "Three", "four", and "seven" are favored by the Western people. "Three" is a perfect number for Western people. Because people believe that the world was made up by sky, earth and ocean in English culture. Because "four" and fair have same pronunciation. So "Four" has associative meaning of fair. "Seven" is a mysterious number for English people. Because they believe the world was created by God in seven days. So the trademark name of "7-up(beverage)" is a successful translation. But "four" is a bad number for Chinese people. Because "four" has same pronunciation with “死(Si)”. It will make people think of death. So Chinese trademark names don't use the number of "four". "Thirteen" is not favored by the Western people. It is a taboo in the Western countries. Because it has associative meaning of ill omen in the Bible.

\section{E. Different Associations of Politics and Economy}

Politics and economy are two mainstream directions of the development of each country. Their position can not be infringed. Because of different politics and economic system, the cultural difference of each country is obvious. “小熊 (Xiao Xiong)" is a Chinese children clothing trademark name. When it exported, its name was directly translated as "Little Bear". Nevertheless, "bear" is a taboo word in the West. It is usually associated with bear market by people. Bear market means that stock market is depressed and dismal. This trademark name is translated without thinking about cultural factors. Accordingly this product would not be accepted by western consumers.

\section{TRADEMARK TRANSLATION UNDER THE INFLUENCE OF CULTURAL DifFERENCES}

It is overwhelming that foreign trademarks rush into the domestic. We can see soar technology of Korea from “三星 (Samsung)”, “乐金 (LG)” and “现代(Hyundai)”. We know mightiness of America from “福特(Ford)”, “劳斯莱斯 (Rolls-Royce)”, “凯迪拉克 (Cadillac)” and “科勒(KOHLER)”; We also perceive mystery of Japan from “松下 (Panasonic)”, “东芝(TOSHIBA)”, “丰田(TOYOTA)” and “三菱 (MITSUBISHI)”; We approve the advance of Germany from “奔驰(Benz)”, “保时捷(Porsche)” and “西门子(Siemens)” These trademarks not only make us know well-know trademarks but also appreciate foreign culture and international amorous feelings. Before putting products into the market, foreign producers have deep thought of trademarks translation, to cater Chinese consumers' consumption psychology.

\section{A. Differences of Individual Thoughts}

Foreign trademark names have characteristics of Western culture obviously. Many of them derived from the Greek Roman mythology, the Bible, modern literature and historic names of people and place. China is an ancient country with five-thousand-year cultural history. Chinese culture has thick oriental characteristics, different from western 
culture. There is one more point, on account of different thoughts, people have individual consumer psychology.

Poison, is a trademark name of exotic perfume. The meaning of poison in English is toxicant. This trademark name show us a kind of reverse thinking. According to the foreign market research, experts found that western women pursuit wildness and adventure. Producers use an extreme word to reflect the characteristics of it. The products develop the sale market by its unique idea of trademark. However, in Chinese traditional customs, women pursuit wildness and adventure rarely. So before it was explored into the Chinese sales market, producers translated “Poison" into “百爱神 (Bai Ai Shen)" in Chinese to obey the cultural habits of Chinese consumers.

In the Han culture, people always pay attention to humility and calm steady character. And Chinese expression of sexual relation is euphemism. A kind of cosmetics' trademark name is "Kiss-Me". It successfully helps people associate with charm and sex appeal of women. Nevertheless, most women in China is not open enough to accept other people's praise about “You are really sexy" with smile at present. It is translated as “奇士美(Qi Shi Mei)” instead of “吻我(Wen Wo)". Because implicative expression of sex and love are advocated by Chinese ethnic peoples.

Chinese thoughts are deeply influenced by confucian culture. It makes Chinese people have conservative ideas and personality. However, western people advocate freedom and openness. So different people affect the translation of trademarks.

\section{B. Differences of Social Customs}

Social customs is cultural norms naturally forming in the long-term joint labor and common life. Although without very strong blinding, it restricts people's words, actions, and ideas etc. Different social customs have a great influence on the translation of trademarks. You should have comprehensive analysis and investigation of life style and customs of advertising target market before doing trademark translation. Otherwise, it will have a negative impact to products' image and sales. Such as “利(Li)”, “九(Jiu)”, “福(Fu)”, “宝(Bao)” and “好(Hao)” were deeply loved by Chinese people. Generally speaking, this is auspicious words what Chinese called. Therefore, some foreign trademark translation also pay attention to this aspect. Trademark names like “家乐福” (CARREFOUR), “美特好”(MEET ALL), “吉利”(JILI), “徐福记”(Xv Fu’s) and “999 感冒灵(Gan Mao Ling)”.

\section{Differences of Religious Belief}

Different nations have different religious beliefs which have their own taboos. There are many typical examples to show differences of Chinese and English religious beliefs in trademark translation. For example, lions have positive meaning in English and they are king of beasts in western Fairy Tales. Lion is the symbol of courage and solemn in British. Lion also is the symbol of mighty in China. It is can be said that there is few differences between Chinese and English culture of lion. However, the trademark name of "GOLDLION" was translated into “金狮(Jin Shi)" in the beginning. Chinese pursue long life without old age and avoid death under the influence of Taoism and Buddhism. Because “金狮(Jin Shi)” has same pronunciation with “今失(Jin Shi)” and “今死(Jin Shi)”, so it was translated into “金 利来(Jin Li Lai)" later. (Pan Hongyan,2010)There is no doubt that it will be consistent with national culture and people's psychology.

\section{Problems of Translation in Chinese and English Trademarks}

Firstly, translated names do not conform to the cultural connotation. When Chinese products exported abroad, it is ignored the differences of culture, so that products are not welcomed by foreign people. For example, “帆船(Fan Chuan)", the trademark name of carpet was translated into "Junk". But Junk not only means sailing shape, but also means waste or castoff in English. So if translated like that, no one will pay attention to it(Xia Yong, 2010). Some Chinese trademark names have good images and symbols in Chinese. But translated directly, some will have completely opposite associated meaning. “金龙(Jin Long)" was translated into "Golden Dragon” literally, it will have evil meaning in western people's eyes.

Secondly, translated names are not very elegant. Some Chinese trademark names not all can be translated literally. Because all kinds of associative meanings are different in Sino-British culture. The meaning of force and fierce is associated with tigers in China, but it is associated with lions in the west. So we must find out no adverse associated meaning in western culture when translate trademark names about animals. Otherwise, it will affect the export of Chinese products.

Thirdly, the trademark names translated depend on pronunciation of words. Some of translated words have bad meaning. The Chinese phonetic alphabet of a trademark probably have same bad meaning with an English word. When translating Chinese trademark names, translators must pay attention to bad associated meaning of some Chinese phonetic alphabets and English words. For example, “茉莉花(Mo Li Hua)”, Chinese famous tea, was exported to Europe, America, and Southeast Asian countries, but not popular in Hong Kong. Because the pronunciation of “茉莉 (Mo Li)" is same like “没利(Mo Li)". (Xia Yong, 2010)This is a typical example of the bad associated meaning of trademark words.

\section{Strategies of TRANSLATION IN ChinESE AND ENGLISH TRADEMARKS}


Successful trademark translations should adapt to national culture and respect national feelings. They need to properly express intrinsic meaning of products and accurately reflect quality of products. This requires translators not only to retain mental sharpness but also sensitive cultural awareness. According to the principles of trademark translation, we can use appropriate methods and techniques to make target language appropriate and accurate without losing source language culture, to promote consumption and improve enterprises' images and interests.

\section{A. Transliteration}

Transliteration is divided into direct transliteration and homophonic transliteration.

Direct transliteration means the method according to the pronunciation of Chinese and English trademark names. Many of Chinese trademarks are based on the method of direct transliteration. For example: beer trademarks YANJING(燕京) and YUNGANG(云冈); sports brands LINING(李宁) and ANTA(安踏); skin care product trademarks MAXAM(美加净) and RISECS(伊贝诗); food and beverage trademarks WA HA HA (娃哈哈) and Jianlibao (健力宝); tobacco trademarks HONGTA(红塔) and MAOTAI(茅台). There are many English trademarks which are based on the method of direct transliteration, such as 摩托罗拉(Motorola), 飞利浦(PHILPS), 西门子(SIEMENS), 柯达(Kodak), 迪斯尼(Disney), 奥迪(Audi), 捷安特(Giant) and 诺基亚(NOKIA) and other classic examples.

Homophonic translation refers to using the words' meaning of auspicious to group words. In order to adapt to customers' cultural and psychological orientation. In addition, "Clean \& Clear", a kind of skin care products, is a typical example. English trademark name was translated into “可伶可俐(Ke Ling Ke Li)” instead of “干净清爽(Gan Jing Qing Shuang)". Customers not only can easily associate it with clean and fresh skin, but also remind people of image of clever and sensible girls. So this product is more popular with young girls. Another example, a trademark name of sports shoes is “PEAK”, translated it into “匹克(Pi Ke)". The clever translator use “奥林匹克运动会(The Olympic Games)” to trigger people’s thinking. And for example, the English trademark name of “乐凯(Le Kai)” is “Lucky”. It was translated using homophonic translation method. This film name is not only easy to remember, but also pleasant to hear. This trademark name translation caters to the psychology of consumers in the English-speaking countries. Because of the meaning of "Lucky" is auspicious, it can quickly grasp the customers' attention. We should avoid using some of Chinese words of taboo. It just likes “死(Si)、败(Bai)” etc.

\section{B. Free Translation}

Free translation is the method of trademark translation from the meaning of trademark words without considering pronunciation of words. The free translation method is usually used for the basically same cultural connotation. For instant, "Forget-Me-Not", a trademark name of perfume, is translated into “勿忘我(Wu Wang Wo)".(Zhu Yifei, 2008) Other examples of English trademark free translation are "Shell", "Microsoft", "APPLE", "Nestle", and "PLAY BOY". “Microsoft", the trademark of computer software company, is free translated into “微软(Wei Ruan)”. “Apple”, the trademark name of computer, is free translated into “苹果(Ping Guo)". "Shell”, the trademark name of oil, is free translated into “壳牌(Ke Pai)". "PLAY BOY”, the trademark of magazine and daily necessities, is free translated into “花花公子(Hua Hua Gong Zi)”. "Nestle”, the trademark of coffee and foods, is free translated into “雀巢(Que Chao)”. Other example, the trademark name of British jewelry is “Blue Dolphin”, is free translated into “蓝海豚(Lan Hai Tun)”. “Walk Man” electric appliances are free translated into “随身听(Sui Shen Ting)”. The translation of “Walk Man” is apt to nature and the meaning of it is more comprehensive than its English trademark name. There are many examples of using free translation to translate Chinese trademark. “长城(Chang Cheng)" lubricating oil is free translated into "Great Wall”. “永久(Yong Jiu)” bicycle is translated into “Forever” using free translation. “熊猫(Xiong Mao)” electric appliance is free translated into "Panda”. “王朝(Wang Chao)” wine is free translated into "Dynasty”.

\section{Non-translation}

Some trademark names of simple letters, Arabic numbers or symbols can not be translated. This situation can be divided into three categories. Firstly, some trademark names consist of a few letters, numbers, or symbols. The meaning of them is clear at a glance. It is easy to understand, so we do not need to translate it. Such as British fashion women's U' db. Secondly, some English trademark names are translated by abbreviating initial letters of each words. For example, "Christian Dior" is world famous cosmetic trademark. Chinese people generally call it CD, although it can be translated as “迪奥(Di Ao)”. And “Calvin Klein” is fashion trademark of America. People generally call it CK. Thirdly, some internationally well-known trademarks do not have to be translated, especially which having long history and top level. Such as Max Mara etc. Foreign trademark names translated using non-translation method are "IBM (computer)" and "555 (cigarette)" etc. Chinese trademark names translated using non-translation method are "TCL (electrical equipment)", "999 (medicine)", "HTC (mobile phone)" and "VV (soymilk)" etc.

\section{CONCLUSION}

On this day, Chinese and western cultures exchange rapidly and vigorously. Trademark translation is a complicated cross-cultural communication activity. Trademark translation is not only the translation on the language level, but also a 
kind of translation of culture. In this paper, the importance of trademark names translation was emphasized through the analysis of excellent and failed examples. We must pay attention to cultural differences in translation of trademarks and pronunciation and memorize of trademark names, reflecting products' characteristics. There are lots of methods concluded in trademark name translation that we can use to achieve successful trademark translation.

Trademark name translation is not easy transformation from one language to another. It is often related to different cultural traditions and psychological differences of customers caused by differences of culture. Trademark translation is one of intercultural translations. Translators need to stand on a level of intercultural translations and have observant awareness of cross culture. At the same time, they need to respect every ethnic customs and use correct methods and skills of translation to make trademarks into customers hearts. Thereby, manufacturers can promote consumption and improve the interests of enterprises.

\section{REFERENCES}

[1] AI Ries. (2009). The 22 Immutable Laws of Marketing. Taiyuan: Shanxi People's Publishing House.

[2] Jiang Mei. (2014). Trademark Translation in the Context of Intercultural Communication. Shanghai: Journal of Shanghai Foreign Economic and Trade University, 21(06):67-74.

[3] Liu Fagong. (2003). On Several Key Problems in Trademark Translation between Chinese and English. China. Translators Journal, (06):70-73.

[4] Lv Huichun. (2010). Considerations of Cultural Influence on Chinese and English Brand Name Translation. Liaoning: Dongbei University of Finance and Economics.

[5] Long Lingyun. (2007). Cultural Differences in Chinese and English Trademarks. Hengyang: Research in Science Education, (07):46-48.

[6] Lian Tiane. (2014). On Chinese-English Translation of Brands Named by Animal Terms from the Perspective of Conceptual Metaphor Theory. Xi'an: Xi'an International studies University.

[7] Nord, Christiane. (1997). Translation as a Purposeful Activity: Functionalist Approaches Explained. Manchester, UK :St. Jerome Pub.

[8] Nida, E. (1993). Language, Culture and Translating. Shanghai: Shanghai Foreign Language Education Press.

[9] Pan Hongyan. (2010). Cultural Differences between Chinese and English Translation of Trademarks. Guangdong: Chinese Business World, (11):419

[10] Zhu Yifei. (2008). Translations of English and Chinese Trademarks in the Context of Intercultural Communication. Liaoning: Journal of Liaoning Administration College, (07):201-202.

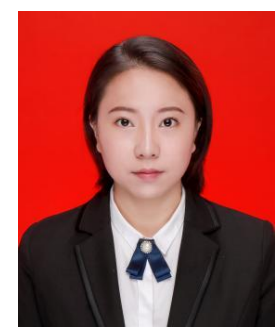

Xuechuan He was born in Datong, Shanxi Province of China in February 1993. She received her bachelor degree in 2016

She is a graduate student in the School of foreign languages, Shanxi Normal University, Shanxi, China in 2018. Her research interest is mainly translation. 